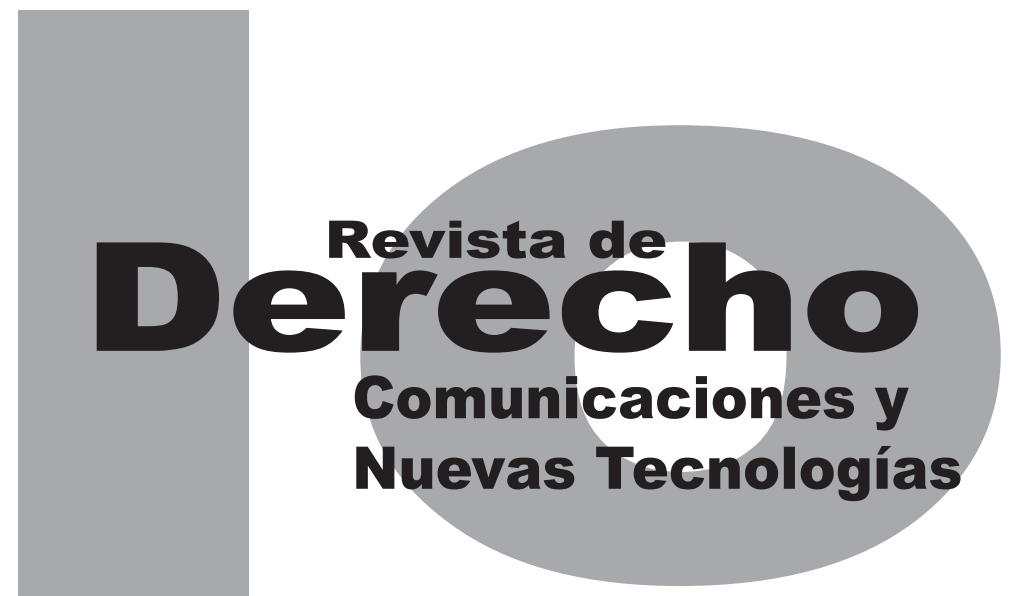

PRINCIPIO de EFICACIA CONSTITUCIONAL DE LA FUNCIÓN DE VIGILANCIA Y CONTROL DE LA SUPERINTENDENCIA DE INDUSTRIA Y COMERCIO EN MATERIA DE TELEFONÍA MÓVIL CELULAR

\author{
Karen Margarita López De ARMAS \\ Catalina Amado Amado \\ Artículo de investigación científica y tecnológica \\ DOI: http://dx.doi.org/10.15425/redecom.12.2014.06 \\ Universidad de los Andes \\ Facultad de Derecho
}

Revista de Derecho, Comunicaciones y Nuevas Tecnologías

No. 12, Julio - Diciembre de 2014. ISSN 1909-7786 


\title{
Principio de eficacia constitucional de la función de vigilancia y control de la Superintendencia de Industria y Comercio en materia de telefonía móvil celular
}

\section{Resumen}

El sector de la telefonía móvil celular (TMC) no es ajeno a múltiples solicitudes y quejas de los usuarios, frente a la efectiva prestación del servicio. Es allí donde cobra vital importancia la intervención del Estado, en cabeza de la Superintendencia de Industria y Comercio (SIC), como organismo que se encarga de la vigilancia y control de los operadores de telefonía celular, con el fin de mejorar la calidad del servicio prestado en aras de implementar y brindar soluciones a problemas de los ciudadanos, y la protección de los derechos de los usuarios suscriptores de servicios de TMC. Esta labor va ligada directamente con la función administrativa, y a sus principios rectores, especialmente al principio de eficacia, que impone el logro de resultados mínimos en relación con los compromisos y responsabilidades impuestas constitucionalmente.

Palabras clave: Principio de eficacia constitucional, Superintendencia de Industria y comercio, vigilancia y control, comunicaciones.

\section{Principle of "Efficacy" in the Colombian Constitution, referred to the supervision and control performed by the Superintendence of Industry and Commerce (SIC) in cellular mobile telephony matters}

\begin{abstract}
The cellular mobile telephony sector in Colombia (TMC for its acronym in Spanish) is not aware to the permanent requests and complaints from customers, who are demanding day by day the properly accomplishment of the service provided. That situation explains why is of vital importance the intervention of the Colombian Government, led by the Superintendence of Industry and Commerce (SIC), entity that has under its responsibilities the supervision and control of the mobile telephony operators. The main goal is to improve the quality of the service provided, in order to implement accurate solutions to unsatisfied customers and to protect the rights from subscribers attached to TMC services. This activity is necessarily connected to the administrative function and its guiding principles, especially the "efficacy", which demand the minimum achievement of outcomes in relation with compromises and responsibilities ordered by the Constitution.
\end{abstract}

Keywords: top of constitutional effectiveness, Superintendence of Industry and Commerce, monitoring and control, communications.

\section{Princípio de eficácia constitucional da função de vigilância e controle da Superintendência de Indústria e Comércio em matéria de telefonia móvel celular}

\section{Resumo}

O setor da telefonia móvel celular (TMC) não é alheio a múltiplas solicitudes e queixas dos usuários, frente à efetiva prestação do serviço. É aí onde cobra vital importância a intervenção do Estado, em cabeça da Superintendência de Indústria e Comércio (SIC), como organismo que se encarrega da vigilância e controle dos operadores de telefonia celular, com o fim de melhorar a qualidade do serviço prestado em aras de implementar e brindar soluções a problemas dos cidadãos, e a proteção dos direitos dos usuários assinantes de serviços de TMC. Este trabalho vai ligado diretamente com a função administrativa, e a seus princípios reitores, especialmente ao princípio de eficácia, que impõe o sucesso de resultados mínimos em relação aos compromissos e responsabilidades impostas constitucionalmente.

Palavras-chave: princípio de eficácia constitucional, Superintendência de Indústria e comércio, vigilância e controle, comunicações. 


\title{
Principio de eficacia constitucional de la función de vigilancia y control de la Superintendencia de Industria y Comercio en materia de telefonía móvil celular*
}

\author{
Karen Margarita López De Armas \\ Catalina Amado Amado**
}

\section{SUMARIO}

Introducción - I. PRINCIPIO DE EFICACIA CONSTITUCIONAL - II. LAS SUPERINTENDENCIAS - A. Función de vigilancia y control que ejercen las Superintendencias - B. Facultad sancionatoria del Estado - C. La Superintendencia de Industria y Comercio (SIC) - 1. Antecedente histórico y desarrollo normativo - III. DESARROLLO DE LAS COMUNICACIONES - A. Historia de las comunicaciones - B. Telefonía móvil celular en Colombia - 1. El espectro radioeléctrico - 2. Antecedente histórico y normativo de la telefonía móvil celular en Colombia - IV. ESTATUTO DE PROTECCIÓN DEL CONSUMIDOR - A. Antecedente histórico y normativo - B. Desarrollo legislativo en Colombia - C. Protección al consumidor en materia de comunicaciones - D. Mecanismos de defensa y trámite - 1. Petición o queja (PQR) - 2. Recurso de reposición - 3. Recurso de apelación - E. Principales quejas de los usuarios en materia de comunicaciones - F. Casos resueltos por la Superintendencia de Industria y comercio en materia de TMC - G. Informe abonados y variación en la telefonía móvil celular - V. SANCIONES - VI. CONCLUSIONES - Referencias

* Cómo citar este artículo: López de Armas, K. M. y Amado Amado, C. (Diciembre, 2014). Principio de eficacia constitucional de la función de vigilancia y control de la Superintendencia de Industria y Comercio en materia de telefonía móvil celular. Revista de Derecho, Comunicaciones y Nuevas Tecnologías, 12. Universidad de los Andes (Colombia).

** Egresadas de la Facultad de Derecho de la Universidad La Gran Colombia. Actualmente trabajan en la Secretaría General del Instituto de Seguros Sociales, hoy en liquidación. Correos electrónicos: kmlopez@iss.gov.co y camadoa@iss.gov.co 
Introducción

Con el paso de los años el servicio de telefonía móvil pasó de ser un servicio lujoso a una herramienta básica y necesaria de comunicación masiva, consolidándose en la actualidad como uno de los sectores de desarrollo económico con más proyección, lo que en la actualidad desembocó en más líneas celulares que habitantes en el territorio nacional.

Nuestro país no ha sido la excepción al acelerado proceso de transformación de las comunicaciones, sin embargo, durante los últimos años el número de quejas de los usuarios a los proveedores del servicio han tenido más eco (problemas crecientes con la efectiva prestación del servicio, con la facturación, con negación de consumos, cláusulas de permanencia, entre otros), lo que nos lleva a preguntarnos si la entidad encargada de ejercer vigilancia y control sobre dichos proveedores, es decir, la Superintendencia de Industria y Comercio, está siendo eficaz en dichas facultades, en consonancia con los principios de la función administrativa, en especial el de eficacia constitucional.

El principio de eficacia de la gestión administrativa no deja de presentar problemas en el campo del derecho administrativo por la multiplicidad de fines que la misma tiene asignados, dicha gestión se traduce en que las autoridades administrativas ostentan cargas relativas al desempeño de sus funciones en aras de implementar y brindar soluciones a problemas de los ciudadanos. La protección de los derechos de los usuarios suscriptores de servicios de co- municaciones quedó radicada en cabeza de la Superintendencia de Industria y Comercio, en virtud de lo dispuesto en el artículo 40 del Decreto 1130 de 1999, sin embargo, según un informe de la Contraloría General de la República a la gestión de la SIC del 2010, se han venido presentando una serie de cuestionamientos sobre las deficiencias en la atención oportuna y eficaz de los diferentes servicios que ofrece esta entidad, principalmente en el tema de comunicaciones, teniendo en cuenta principalmente el aumento considerable de la demanda en este tipo de servicios.

Por lo tanto, el objetivo de este documento es evaluar el desarrollo durante los últimos tres años del principio de eficacia administrativa en la función de vigilancia y control de la Superintendencia de Industria y Comercio en materia de comunicaciones.

Teniendo en cuenta la temática propuesta, el enfoque dominante es el cualitativo, el cual es eminentemente teórico. Adicionalmente, el tipo de investigación es el descriptivo, ya que se efectúo una búsqueda de bibliografía sobre el principio de eficacia de la función de vigilancia y control ejercido por la Superintendencia de Industria y Comercio (SIC) en materia de telefonía celular, sin dejar de lado el enfoque cuantitativo, toda vez que se analizan cifras materializadas en estadísticas orientadas a establecer, precisamente, la eficacia en las funciones anteriormente mencionadas. 


\section{PRINCIPIO DE EFICACIA CONSTITUCIONAL}

Existen en el ordenamiento jurídico colombiano una serie de principios de rango constitucional que orientan la función administrativa en todas sus aristas. De acuerdo con el artículo 209 de la Constitución, "la función administrativa está al servicio de los intereses generales y se desarrolla con fundamento en los principios de igualdad, moralidad, eficacia, economía, celeridad, imparcialidad y publicidad [...]" (negrilla fuera de texto). Con fundamento en este artículo, no es suficiente que la administración tenga como objetivo principal el interés general, sino que es un imperativo constitucional que los fines del Estado se desarrollen bajo los principios de eficacia, celeridad y economía.

Ahora bien, al hacer referencia al tema anterior, Parejo sostiene (1998) lo siguiente: “1. Refiere su contenido a la administración subjetivamente considerada, al establecer el mandato de que esta sirva, con objetividad, el interés general, actuando, para ello, conforme a determinados principios y con sometimiento a la ley y al derecho".

La función administrativa la define Penagos (2004) como la actividad concreta dirigida mediante una acción positiva, a la realización de los fines concretos de seguridad, progreso y bienestar de la colectividad. Función por lo tanto encaminada a orientar la actividad individual, allí donde esta se revele como insuficiente para los objetivos que sean de interés colectivo y a la prestación de bienes o servicios necesarios para asegurar la conservación y el bienestar común.

Al estudiar el accionar de la función administrativa, se analiza no sólo la actividad en sí, sino además quién la ejerce y los procedimientos que utiliza para efectivizar al máximo el poder constitucional de que gozan los entes encargados de su desarrollo; esta función se sirve de facultades especiales reglamentadas, que a su vez se dirigen a controlar y limitar las actividades que satisfacen a la comunidad.

Ahora bien, entendida la función administrativa como la actividad del Estado organizada en la estructura jurídica del poder público, encaminada a satisfacer los intereses generales dentro del marco del desarrollo de sus funciones, y con base en los principios constitucionales anteriormente mencionados, se destaca uno por su incidencia en el goce efectivo de los derechos prestacionales de los asociados o administrados, en cuanto a usuarios de los servicios públicos: es el principio constitucional de eficacia en la función de la Superintendencia de Industria y Comercio, en cuanto al control y vigilancia que en materia de comunicaciones está obligada a desarrollar. Este principio está íntimamente ligado a los fines esenciales del Estado, postulado este contenido en el artículo 2 de la carta. Al respeto, sostiene la Corte Constitucional:

[...] dentro de los fines esenciales del Estado está servir a la comunidad, promover la prosperidad general y garantizar la efectividad de los principios, derechos y deberes consagrados en la Constitución [...]. Con fundamento en esto, 
la jurisprudencia de esta Corte ha protegido el denominado principio de eficacia de la administración pública, según el cual las autoridades administrativas ostentan cargas relativas al desempeño de sus funciones, en orden a implementar y brindar soluciones a problemas de los ciudadanos. Dichas problemas constituyen deficiencias atribuibles a deberes específicos de la administración, y así las mencionadas soluciones han de ser ciertas, eficaces y proporcionales a estos (T-733, 2009).

Por consiguiente, el principio constitucional de eficacia de la función administrativa, como lo sostiene la Corte Constitucional, imposibilita a los organismos administrativos a permanecer inactivos, ante situaciones que afecten a los ciudadanos y que por el contrario deben impulsar su accionar a fin de evitar que los particulares, en este caso, los operadores de telefonía celular, aprovechen la posición dominante y deleguen o impongan cargas propias a los usuarios.

En virtud al principio de eficacia, se observa que cada uno de los procedimientos adoptados por un organismo estatal estará encaminado a lograr su finalidad, con fundamento en los fines del Estado y los principios que rigen la actividad pública. De ahí que la puesta práctica de este principio trae ligado directamente el deber de actuación de la administración, y de la efectiva ejecución de las medidas y procedimientos con que han sido envestidos constitucionalmente, para hacer cumplir los compromisos adquiridos con los administrados, y no solo con la aprobación sobre aquello en lo que es estricta y legalmente necesario su intervención.
A su turno, la Corte Suprema de Justicia (Alcibiades Salamanca León Vs. Tribunal Superior de Yopal, 2008), analiza este principio, en el cual se enmarca la función de la administración pública:

[...] 4. EFICACIA: Este principio implica el compromiso de la Carta con la producción de efectos prácticos de la acción administrativa. Se trata de abandonar la retórica y el formalismo para valorar el cumplimiento oportuno, útil y efectivo de la acción administrativa. El principio impone el logro de resultados mínimos en relación con las responsabilidades confiadas a los organismos estatales, con miras a la efectividad de los derechos colectivos e individuales.

La eficacia está contenida dentro de la Carta como pilar fundamental de la actividad pública, en el artículos 2, al establecer como uno de los fines esenciales del Estado el de garantizar la efectividad de los principios, deberes y derechos consagrados en la Constitución; en el 209 como principio de obligatoria observancia de los organismos que ejercen la función administrativa; en el 365 como uno de los objetivos de la prestación de los servicios públicos; y, por último, en el 256, numeral 4, 268, numeral 2, 277 , numeral 5 y 343, relacionados con el control de gestión y resultados (SU086, 1999).

Así mismo, la Corte Constitucional ha manifestado:

[...] debe recordarse que por expreso mandato constitucional, la función pública debe regirse por los principios de eficacia y eficiencia en el servicio, los cuales son también pautas de comportamiento del Estado Social de Derecho 
y uno de los mecanismos para desarrollar los fines esenciales del Estado. (T-559, 1998)

Finalmente, la misma corporación también ha manifestado:

[...] La efectividad de los derechos se desarrolla con base en dos cualidades, la eficacia y la eficiencia administrativa. La primera relativa al cumplimiento de las determinaciones de la administración y la segunda relacionada con la elección de los medios más adecuados para el cumplimiento de los objetivos. Es por ello que las dos cualidades permiten la verificación objetiva de la distribución y producción de bienes y servicios del Estado destinados a la consecución de los fines sociales propuestos por el Estado Social de Derecho. (T-068, 1998)

\section{LAS SUPERINTENDENCIAS}

Las Superintendencias son organismos que desarrollan ciertas funciones que corresponden a los ministerios, pero por motivos de rapidez de la administración y por cuestiones técnicas se les ha confiado a dichos organismos. Su origen se da en la Ley 45 de 1923, por medio de la cual se creó la Superintendencia Bancaria. Estos organismos ocupan un grado intermedio entre los ministerios y los establecimientos públicos, su naturaleza es de carácter administrativo y pertenecen al sector central.

En basta jurisprudencia de la Corte Suprema de Justicia, particularmente en las fechadas entre el 22 de enero de 1970 y el 11 de septiembre de 1975 (Penagos, 2004), se ha sostenido con entera claridad que las superintendencias son organismos administrativos que hacen parte de la estructura de los ministerios, a los cuales se encuentran adscritas y cuyas funciones son, por lo mismo, cumplir alguna de las atribuciones administrativas que la Constitución encarga al presidente de la República y permite delegar en los ministros del despacho.

\section{A. Función de vigilancia y control que ejercen las Superintendencias}

Sea lo primero señalar los conceptos de vigilancia y control. El primero proviene del latín vigilantia que, según el Diccionario de la lengua española, significa "cuidado y atención exacta en las cosas que están a cargo de cada uno". (https//www.rae.es, 2013). En tal sentido, las Superintendencias son la instancia de intervención del Estado, que observa la conducta tanto de los proveedores de redes y servicios como del sector en general, sin que implique algún cargo o interferencia directa en sus actividades, algunas veces sin que el vigilado se dé cuenta siquiera de que está siendo objeto de supervisión. Son típicas funciones de vigilancia supervisar el cumplimiento de las disposiciones legales, reglamentarias y regulatorias que expida el Gobierno nacional (López, 2010, pág. 495).

Por otro lado, el concepto de control proviene del término francés contrôlae y significa comprobación, inspección, fiscalización, intervención. También puede hacer referencia al dominio, mando, preponderancia o a la regulación sobre un sistema. Este sería el grado más alto de intervención del Estado respecto a la competencia de vigilancia en la instancia de control, 
que eventualmente podría intervenir de forma directa en los servicios de telecomunicaciones (López, 2010, pág. 495).

Es una tradición constitucional y legal en Colombia que las superintendencias ejerzan funciones de inspección y vigilancia, criterio que se reafirma en la Constitución Política de 1991, artículo 189, numeral 24 , al señalar funciones de inspección, vigilancia y control sobre algunas entidades, y que se atribuyen al presidente de la República, quien a su vez las delega en las diversas Superintendencias, por autorización constitucional y legal, según el artículo 211 de la Constitución (López, 2010, pág. 495).

El presidente de la República, como cabeza del poder ejecutivo, ostenta una serie de funciones enmarcadas constitucionalmente que no puede asumir directa y personalmente, entre ellas las de vigilancia y control. Por esto es lógico que la ley, en desarrollo del articulado superior, anuncie el adelantamiento de las labores inherentes a esa facultad presidencial por organismos especializados competentes para desarrollarlas con la eficacia y la rigurosidad requeridas, pues, de otra manera, los objetivos superiores quedarían desvirtuados al tornarse ilusorias las mencionadas funciones.

La Corte Constitucional ha manifestado que la delegación es el

“[...] requisito de la ley previa para delegar funciones presidenciales, e incluso para que las autoridades administrativas puedan, a su vez, delegarlas en sus subalternos [...]. Las Superintendencias tienen el carácter de unidades e ejecutoras, puesto que sus actividades específicas se realizan dentro de sectores que corresponden a la órbita de acción de determinados ministerios [...]." (C-337, 1993)

El desarrollo de las funciones de vigilancia y control ha sido confiado a las Superintendencias, las cuales, no obstante, no actúan de forma autónoma ni independiente, pues lo hacen bajo la dirección y orientación del presidente de la República, quien es el titular constitucional de dicha función (C-397, 1995).

El artículo 4 del Decreto 1050 de 1968 estableció que las Superintendencias fueran organismos adscritos a un ministerio, que, en el marco de la autonomía administrativa y financiera que les señalara la ley, cumplieran algunas funciones que correspondían al presidente de la República como suprema autoridad administrativa, y las que la ley les asignara. De esta manera se institucionalizaba cabalmente y en su integridad a las Superintendencias como parte de la estructura de la administración pública en el orden nacional, antecedente normativo y organizacional que fue tenido en cuenta por el constituyente de 1991, quien las contempló expresamente como parte de la misma. El numeral 7 del artículo 150 dispone que su creación corresponde al Congreso por iniciativa del gobierno, según las voces del artículo 154 constitucional (Vidal, Díaz, \& Rodríguez, 2005).

\section{B. Facultad sancionatoria del Estado}

El ius puniendi del Estado se entiende como el poder que tienen los órganos que lo componen, 
tanto penales como administrativos, con el fin de lograr el funcionamiento del aparato estatal. Siguiendo las palabras de la Corte Constitucional (C-160, 1998), la misma se traduce en una "potestad que no solo es ejercida por los jueces, sino por diversos funcionarios de la administración, que, para lograr el cumplimiento de las funciones que les han sido asignadas, deban hacer uso de este, para garantizar el adecuado funcionamiento del aparato estatal.

El mismo Tribunal añade que el poder del Estado se traduce en una serie de atribuciones, facultades o competencias que se radican en cada una de las ramas del poder y que se materializan en la existencia de distintas funciones, que constituyen el instrumento para el cumplimiento de los cometidos estatales (C-853, 2005).

Entonces, en el poder sancionador se congregan, junto al derecho penal, otras modalidades del ejercicio sancionador, como los casos del contravencional o policivo, disciplinario, correccional o correctivo, y al que la Corte Constitucional le ha agregado otra manifestación más: el derecho de punición por indignidad política o impeachment (Ramírez, 2007). De esta manera, la facultad de que goza el Estado para aplicar sanciones por la transgresión del ordenamiento jurídico es una, pero la misma se manifiesta de diversas formas (T-597, 1996).

La facultad sancionatoria de las Superintendencias se presenta para hacer cumplir un cuerpo normativo. Si no existieran dichas facultades, la regulación resultaría inocua, puesto que no habría forma de que el Estado ejerciera su poder coercitivo y por ende de regulación de los bienes y servicios que presta. (Vidal, Díaz, \& Rodríguez, 2005, pág. 1011).

\section{A juicio de la Corte Constitucional:}

[...] la potestad sancionadora de la Administración permite asegurar la realización de los fines del Estado, al otorgarle a las autoridades administrativas la facultad de imponer una sanción o castigo ante el incumplimiento de las normas jurídicas que exigen un determinado comportamiento a los particulares o a los servidores públicos, a fin de preservar el mantenimiento del orden jurídico como principio fundante de la organización estatal. (C-818, 2005)

Igualmente, respecto a la potestad sancionatoria del Estado, el alto Tribunal Constitucional sostuvo:

Dentro de las manifestaciones del poder sancionatorio en el Estado Social de Derecho, aparece la potestad sancionadora en materia administrativa al lado de la potestad sancionadora en materia penal. El reconocimiento de la primera, que ha sido posterior en el tiempo, ha venido aparejado con el incremento de las actividades administrativas, el cual a su vez se ha producido por el cambio en la concepción del papel del Estado contemporáneo. Si en sus inicios el Estado constitucional liberal se justificaba como garante de los derechos y libertades individuales, pero sin ningún compromiso con la verdadera promoción de los mismos, el Estado social de Derecho se concibe como el promotor de toda la dinámica social hacia la efectividad de tales derechos y garantías. A estos efectos, el Estado ha sido llamado al cumplimiento de nuevas actividades y al ejercicio 
de funciones como las de planeación e intervención de la economía, la redistribución del ingreso para garantizar la satisfacción de las necesidades básicas asociadas con la efectividad de los derechos fundamentales, la protección del medioambiente, etc. (C-506, 2002)

En consecuencia, la facultad o potestad sancionatoria del Estado se traduce en un verdadero control coercitivo para la protección efectiva de los derechos de los ciudadanos, convirtiéndose en el instrumento último de que goza el Estado para efectivizar su actividad.

\section{La Superintendencia de Industria y Comercio (SIC)}

\section{Antecedente histórico y desarrollo normativo}

El antecedente de las Superintendencias se ubica en la mitad del siglo XX, cuando el país registró un crecimiento industrial considerable, razón por la cual se dieron cambios en la regulación. Por esto, en el año 1959, con la Ley 155 del mismo año, se estableció la intervención estatal en la fijación de los precios, es decir, la necesidad de creación de un organismo dirigido a controlar y, por supuesto, vigilar la actividad del Estado, se produce en el sector económico.

No fue sino hasta 1968, con la expedición del Decreto 2974 del 3 de diciembre del mismo año, que el Gobierno nacional reestructuró el Ministerio de Fomento, cambió su nombre a Ministerio de Desarrollo Económico y, en el capítulo II, artículos 25 al 39, creó la Superintendencia de Industria y Comercio.
A comienzos de la administración del expresidente César Gaviria, en el año 1990, se inició el llamado "proceso de modernización estatal". En consecuencia, se reestructuró la Superintendencia de Industria y Comercio, con el fin de armonizar su labor con los mandatos de la nueva constitución y establecer un marco propicio para el cumplimiento de los principios propios de función administrativa.

En materia de protección al consumidor, la Superintendencia ejercería a prevención las atribuciones jurisdiccionales previstas en el artículo 145 de la Ley 446 de 1998, como lo son: ordenar el cese y la difusión correctiva de los mensajes publicitarios que contienen información engañosa y ordenar la efectividad de las garantías de bienes y servicios establecidas en las normas de protección al consumidor, entre otras.

El 29 de junio de 1999 se expidió el Decreto 1130, el cual le otorgó a la Superintendencia de Industria y Comercio la facultad de inspeccionar y vigilar lo relativo al régimen de libre y leal competencia en los servicios no domiciliarios de comunicaciones, para lo cual se le dio la facultad de aplicar lo establecido en todas las normas relativas a promoción de la competencia y prácticas comerciales restrictivas. Igualmente, se le confió la protección de los derechos de los usuarios y suscriptores de los servicios no domiciliarios de telecomunicaciones.

Durante el año 2009 se expidieron las leyes 1335, 1340, 1341 y 1369, que le asignaron nuevas funciones a la Superintendencia de Industria y Comercio. 
La Superintendencia de Industria y Comercio es un organismo de carácter técnico, con personería jurídica (Ley 1151, artículo 71, 2007), adscrito al Ministerio de Comercio, Industria y Turismo, con autonomía administrativa y presupuestal, creado mediante Decreto 623 de 1974 y reestructurado mediante los decretos 2153 de 1992, 3523 de 2009 y 4886 de 2011.

Con la promulgación de la Ley 1341 de 2009, la Superintendencia de Industria y Comercio asumió la competencia en materia de protección de usuarios de los otros servicios domiciliarios de telecomunicaciones. De acuerdo con lo previsto en el artículo 73 de la Ley 1341 (Imprenta Nacional de Colombia, 2009), "A las telecomunicaciones, y a las empresas que prestan los servicios de telefonía pública básica conmutada, telefonía local móvil en el sector rural y larga distancia no les será aplicable la Ley 142 de 1994 respecto de estos servicios [...]".

En este orden de ideas, la competencia en materia de protección de los derechos de los usuarios, suscriptores y consumidores de servicios de telecomunicaciones quedó radicada en cabeza de la SIC, en virtud de lo dispuesto en el artículo 40 del Decreto 1130 de 1999.

También en el año 2011 se expidió la Ley 1480, mejor conocida como el nuevo Estatuto del Consumidor, que entró a regir el 12 de abril de 2012, y que mantiene a la Superintendencia de Industria y Comercio como la entidad encargada de velar por la protección de los derechos del consumidor; le asigna nuevas funciones y amplía el ámbito de sus competencias, lo cual implica un nuevo reto para este organismo (Superintendencia de Industria y Comercio).

Igualmente, en el año 2011, mediante el Decreto 4886 de 2011, artículo 13, se crean las funciones de la Dirección de Investigación de Protección a Usuarios de Servicios de Comunicaciones, adjudicando así a una dirección autónoma la protección que en materia de comunicaciones requieren los usuarios del servicio.

Figura 1. Organigrama de la Superintendencia de Industria y Comercio (SIC)

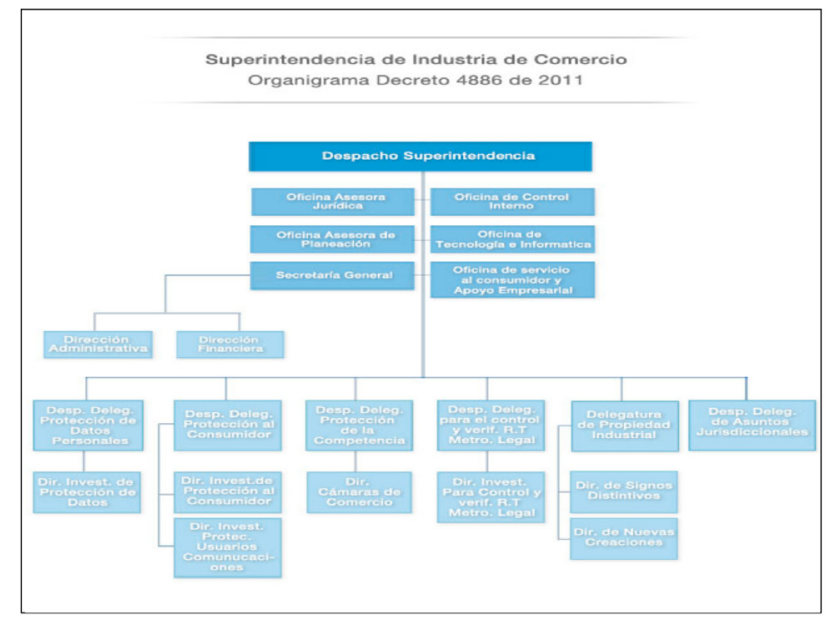

Fuente: Página web de la Superintendencia de Industria y Comercio, http://www.sic.gov.co/es/perfiles-directivos-y-organigrama-institucional.

El Ministerio de Industria y Comercio, mediante Decreto 1130 de 1999, trasladó la facultad sancionatoria que recaía en cabeza del Ministerio de las Tecnologías de la Información y las comunicaciones (Mintic) a la Superintendencia de Industria y Comercio.

Entre las funciones más relevantes de la SIC contempladas en el numeral 36 del artículo 1 del Decreto 4886 de 2011 se encuentran la de 
“imponer, previa investigación, de acuerdo con el procedimiento aplicable, sanciones por violación de las normas sobre protección al consumidor y del régimen de protección a usuarios de los servicios de telecomunicaciones"; así como la establecida en el numeral 32 del mismo artículo:

Velar en los términos establecidos por la ley y la regulación expedida por la Comisión de Regulación de Comunicaciones, por la observancia de las disposiciones sobre protección al consumidor y los usuarios de los servicios de telecomunicaciones y dar trámite a las quejas o reclamaciones que se presenten.

Por otro lado, y en consonancia con la Ley 1341 de 2009 y la Circular expedida por el Mintic número 00003 del 20 de agosto de 2009, la SIC es el organismo competente para ejercer las funciones de vigilancia y control de los diferentes operadores de telecomunicaciones, en consiguiente, es el órgano estatal responsable de la protección de los usuarios y suscriptores de dichos servicios.

Es necesario mencionar que la Comisión Reguladora de Comunicaciones es el organismo "encargado de promover la competencia, evitar el abuso de posición dominante y regular los mercados de las redes y los servicios de comunicaciones; con el fin de que la prestación de los servicios sea económicamente eficiente, y refleje altos niveles de calidad" (Comisión Reguladora de Comunicaciones, 2014). En ejercicio de estas facultades la CRC expidió las Resoluciones 3066 de 2011 y 4296 de 2013, creando así una normativa especial para el servicio de comunicaciones.
En consecuencia, la armonía entre los dos organismos, la CRC y la SIC, materializa la aplicación de las normas de regulación y protección del derecho de consumo en materia de comunicaciones, la primera, expidiendo la regulación y, la segunda, aplicando la normativa bajo las funciones de vigilancia y control que le otorga la ley.

\section{DESARROLLO DE LAS COMUNICACIONES}

\section{A. Historia de las comunicaciones}

En el marco del desarrollo de la tecnología, la humanidad ha pasado por varias etapas para su consolidación, entre ellas se encuentran:

- Las señales de humo.

- Tambores convenientemente espaciados que actuaban como repetidores.

- Palomas mensajeras.

- Sistema de mensajeros (postas a pie o a cabaIlo, como el pony express en EE. UU.).

Posteriormente se crea el telégrafo óptico en 1790 en Francia, en donde se utilizaron los avances en óptica que produjo el telescopio. Esta máquina se origina por la necesidad de enviar información a distancia en el período revolucionario francés, para finales del siglo XVII; no era un servicio público sino que tenía fines militares y de gobierno.

Tiempo después aparece el telégrafo eléctrico en Estados Unidos, cuyo sistema fue ideado por 
Samuel Morse y consistía en utilizar una combinación de breves puntos, largos y no pulsos para representar los diferentes caracteres del alfabeto y los números; utilizaba la electricidad para transmitir información.

En Colombia, bajo el gobierno de Manuel Murillo Toro, se transmitió el primer mensaje telegráfico de Bogotá a Mosquera el 1 de noviembre de 1865, y este se considera como el día de las telecomunicaciones.

Luego aparece la codificación, ya que el código Morse era muy impreciso, dando origen al código telegráfico, que utilizaba pulsos, que tomaron el nombre de "bit" (es una unidad de medida de almacenamiento de información; es la mínima unidad de memoria obtenida del sistema binario y representada por 0 o 1.) (Unidades de medida de almacenamiento de información. S.F.).

Finalmente, y luego de la invención del teléfono por Alexander Graham Bell en 1876, aparecen las telecomunicaciones con el sistema de la telefonía, que es el envío de voz a distancia, generalmente por medios eléctricos, alámbricos o inalámbricos (Torres, 2002).

Para la década de los setenta, Martin Cooper, considerado como "el padre de la telefonía celular", introdujo el primer radioteléfono en 1973 en los Estados Unidos, mientras trabajaba para Motorola. Pero fue hasta 1979 que apareció el primer sistema comercial en Tokio (Japón) por la compañía NTT (Nippon Telegraph \& Telephone Corp.) (Adecom, movilidad y eficiencia, 2001).
En 1981, en los países nórdicos, se introduce un sistema celular similar a AMPS (Advanced Mobile Phone System) (www.riunet.upv.es, SF). Por otro lado, en los Estados Unidos, gracias a que la entidad reguladora de ese país adopta reglas para la creación de un servicio comercial de telefonía celular, en octubre de 1983 se pone en operación el primer sistema comercial en la ciudad de Chicago (www.timerime.com, SF). A partir de entonces, en varios países se diseminó la telefonía celular como una alternativa a la telefonía convencional alámbrica.

La tecnología inalámbrica tuvo gran aceptación, por lo que a los pocos años de implantarse se empezó a saturar el servicio, y hubo la imperiosa necesidad de desarrollar e implementar otras formas de acceso múltiple al canal y transformar los sistemas analógicos a digitales, para darles cabida a más usuarios. Para separar una etapa de la otra, la telefonía celular se ha categorizado por generaciones (Adecom, movilidad y eficiencia, 2001). Estas generaciones son 1G, que apareció en el año de 1979 y se caracterizó por ser analógica; la 2G, que arribó hasta 1990 y se caracterizó por ser digital; la generación 2.5G, que encontró su entrada hacia el año 2001; la 3G, que apareció en el 2002, y la generación 4G, utilizada en la actualidad (www. utp.edu.co, SF). 
Figura 2. Grandes hitos de las comunicaciones y tiempo transcurrido entre ellos.

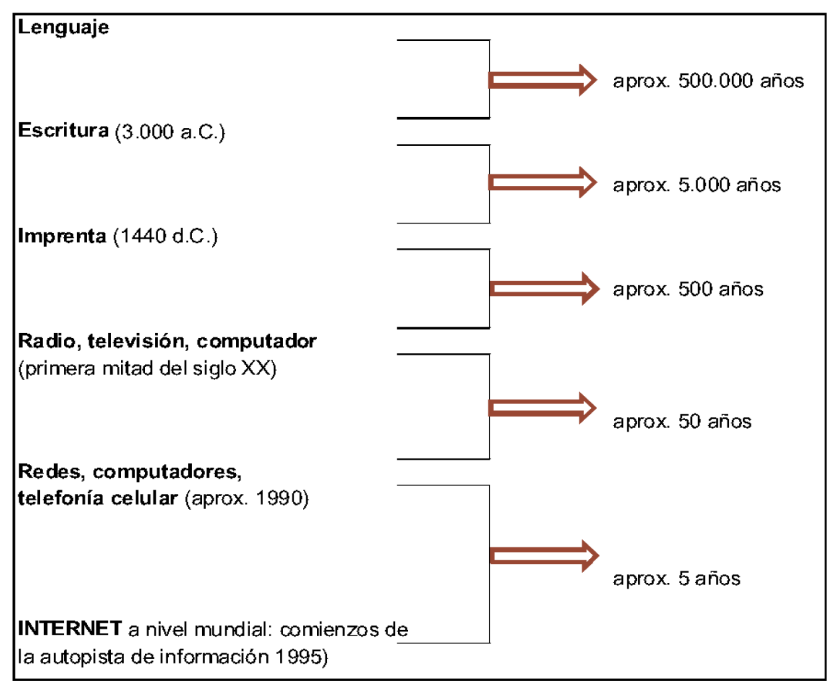

Fuente: (Torres, 2002)

\section{B. Telefonía móvil celular en Colombia}

\section{El espectro radioeléctrico}

Antes de profundizar en el tema de la telefonía celular en Colombia, se hace necesario realizar unas precisiones conceptuales sobre el espectro electromagnético o radioeléctrico, entendido por la Corte Constitucional (T-360, 2010) como "una franja de espacio alrededor de la Tierra a través de la cual se desplazan las ondas radioeléctricas que portan diversos mensajes sonoros o visuales. Su importancia reside en ser un bien con aptitud para transportar información e imágenes a corta y larga distancia”.

En Colombia, la telefonía móvil celular forma parte de las Tecnologías de la Información y las Comunicaciones, definidas como "el conjunto de recursos, herramientas, equipos, programas informáticos, aplicaciones, redes y medios, que permiten la compilación, procesamiento, almacenamiento, transmisión de información como voz, datos, texto, video e imágenes" (Contraloría, 2010).

La Ley 1341 creó la Agencia Nacional del Espectro, ANE, cuyo objetivo es "brindar el soporte técnico para la gestión y la planeación, la vigilancia y control del espectro electromagnético, en coordinación con las diferentes autoridades que tengan funciones o actividades relacionadas con el mismo" (Congreso, 2009). Otro deber importante encomendado a esta entidad, y así manifestado por la Corte Constitucional, es el de "adelantar investigaciones a que haya lugar, por posibles infracciones al régimen del espectro definido por el Ministerio de Tecnologías de la Información y las Comunicaciones así como imponer sanciones, con excepción de lo dispuesto en el artículo 76 de la Constitución Política (T-360, 2010).

La Agencia Nacional del Espectro lo define como "el medio por el cual se transmiten las frecuencias de ondas de radio electromagnéticas que permiten las telecomunicaciones (radio, televisión, Internet, telefonía móvil, televisión digital terrestre, etc.), y son administradas y reguladas por los gobiernos de cada país" (Agencia Nacional del Espectro, 2013).

Sobre el espectro radioeléctrico, la Unión Internacional de Telecomunicaciones (UIT), organismo especializado de las Naciones Unidas, ha dicho lo siguiente: 
Las frecuencias del espectro electromagnético usadas para los servicios de difusión y servicios móviles, de policía, bomberos, radioastronomía, meteorología y fijos [...]. No es un concepto estático, pues a medida que avanza la tecnología se aumentan (o disminuyen) rangos de frecuencia utilizados en comunicaciones, y corresponde al estado de avance tecnológico. (Agencia Nacional del Espectro, 2013)

Figura 3. Principales servicios del espectro radioeléctrico

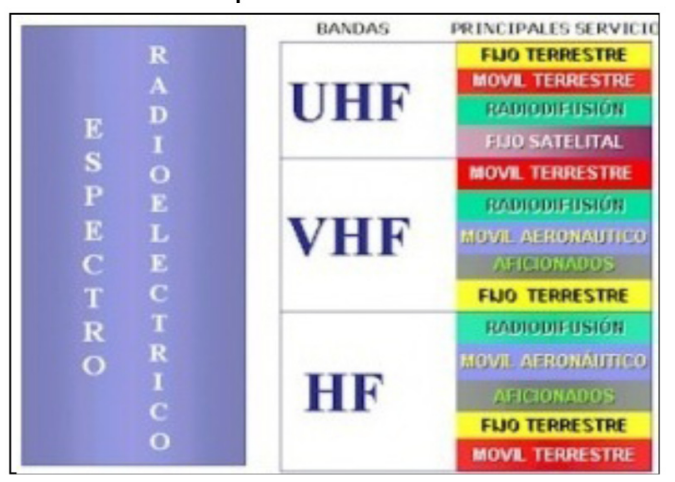

Fuente: (Agencia Nacional del Espectro, 2013)

El artículo 75 de la Constitución determinó la naturaleza del espectro electromagnético como “bien público inenajenable e imprescriptible sujeto a la gestión y control del Estado". Más adelante (art. 101), "Io clasificó como un elemento integrante del territorio colombiano" (T-360, 2010).

\section{Antecedente histórico y normativo de la telefonía móvil celular en Colombia}

En Colombia, la Telefonía Móvil Celular (TMC) se aprobó con la Ley 37 de enero de 1993, la cual permitió al Ministerio de Comunicaciones adjudicar la concesión del servicio de Telefonía Mó- vil Celular, reglamentada con el Decreto 741 del 20 de abril de 1993. Por múltiples circunstancias, la TMC llega al país quince años después de inaugurada la primera red móvil en Japón (3 de diciembre de 1979) y se instala como tecnología de primera generación, cuando ya existía tecnología digital de segunda generación, lo que significa que Colombia tuvo un desarrollo lento de la TMC, porque se recorrió un camino que ya había sido transitado por los países pioneros de este servicio, y no tuvieron en cuenta los adelantos existentes para la época. En conclusión, se instaló una tecnología obsoleta (Contraloría, 2010).

El servicio de telefonía celular en el país se dividió en tres zonas de cobertura: Norte, Occidente y Oriente. En cada zona se habilitaron dos empresas, una de capital privado y otra de capital mixto (con inversión pública y privada), cada una en una banda diferente (Latorre, 2013). En ese año se instaló la infraestructura para el funcionamiento del servicio, y el 1 de Junio de 1994 se realizó una llamada desde Bogotá a Nueva York que comunicó a María Cristina Mejía, la presidenta de Celumóvil (que después se convertiría en Comcel) con Carlos “El Pibe” Valderrama y Julio Mario Santo Domingo (Celulares móviles, 2012).

Las empresas de telefonía celular emprendieron una carrera hacía la fusión y así lograron un mayor crecimiento y cobertura nacional. Comcel, hoy Claro (controlada por América Móvil), y Movistar (propiedad de Telefónica de España) se fusionaron. Posteriormente, a finales de 2003 nació Colombia Móvil con su marca Ola, que lue- 
go se convertiría en Tigo. Igualmente, entró al mercado Uff Móvil, que nace en noviembre de 2010 y, finalmente, en el año 2013 la compañía británica entra a competir con Virgin Mobile Latín América (VMLA) (kienyke.com, 2013).

En Colombia, el servicio de Telefonía Móvil CeIular (TMC) ha registrado los mayores niveles de incremento en cobertura, así como de generación de ingresos, tanto para la industria como para el país, como ningún otro servicio de telecomunicaciones. Es por esto que la tendencia en el desarrollo tecnológico a nivel mundial se ha centrado en la TMC, a fin de ofrecer nuevos productos, mediante la oferta de diferentes portafolios de servicios, mejorando los estándares de calidad y cubriendo nuevas necesidades surgidas con la evolución de las TIC (Contraloría, 2010).

\section{ESTATUTO DE PROTECCIÓN DEL CONSUMIDOR}

\section{A. Antecedente histórico y normativo}

La normativa referente a la protección al consumidor es una rama del derecho que tiene un desarrollo reciente en nuestro país, aunque sus orígenes se remontan al derecho romano. Esta rama evolucionó a través de los momentos históricos más significativos, tales como la Edad Media, la Revolución Industrial, la Revolución francesa. Se institucionalizó en los Estados Unidos con la primera organización de consumidores (National Consumers League, en 1899), y su protección de manera comunitaria se dio a partir de la firma del Tratado de Roma (1957) (Protección, garantías y eficacia de los derechos del consumidor en Colombia, 2010).

\section{B. Desarrollo legislativo en Colombia}

La protección al consumidor hace referencia al conjunto de normas que regulan las relaciones de consumo de bienes y servicios. La concepción de consumidor ha sido definida por la Corte Suprema de Justicia: es la persona o sujeto que contrata con el propósito de satisfacer las necesidades ya sean propias, familiares o sociales, relacionadas con el bien o el servicio.

En este orden de ideas, para estos efectos estima la Corte que, con estrictez, siempre será forzoso indagar en torno a la finalidad concreta que el sujeto-persona, natural o jurídica, persigue con la adquisición, utilización o disfrute de un determinado bien o servicio, para reputarlo consumidor solo en aquellos eventos en que, contextualmente, aspire a la satisfacción de una necesidad propia, privada, familiar, doméstica o empresarial -en tanto no esté ligada intrínsecamente a su actividad económica propiamente dicha, aunque pueda estar vinculada, de algún modo, a su objeto social-, que es lo que constituye el rasgo característico de una verdadera relación de consumo. (Servicio aéreo del Vaupés - Selva Limitada Vs. Fábrica estatal de aviación de KIEV - AVIANT - , 2005)

Ahora bien, en cuanto a los antecedentes normativos del derecho de consumo en Colombia, cabe mencionar que a pesar de que la protección a este derecho se presentaba vía Código Civil y posteriormente con el Código de Comercio, las mismas eran insuficientes por la cantidad de 
requisitos, términos, acciones dispendiosas que lograban disuadir al consumidor de iniciar un proceso judicial. Es por esto que en 1971 se expidieron las primeras normas para salvaguardar a los consumidores, el Decreto 2416 de 1971 y, posteriormente, el Código Sanitario Nacional (Protección, garantías y eficacia de los derechos del consumidor en Colombia, 2010).

No fue sino hasta 1981 (Ley 73) que el legislativo consagró la intervención del Estado, otorgándole facultades de regulación en la comercialización de bienes y servicios para tutela del consumidor, regulando dicha actividad en varios decretos, entre otros, el 1441 de 1982, que reguló la organización, vigilancia y control de las asociaciones de consumidores.

Posteriormente se expidió el Decreto 3466 de 1982, Estatuto del Consumidor, consolidándose así una normativa idónea que recopiló es una sola legislación el derecho del consumo.

Años más tarde, y con la expedición de la Constitución de 1991, se estableció en el artículo 78 la regulación del control de calidad de los bienes y servicios ofrecidos en el mercado, así como la información que deben contener y la responsabilidad que acarrea la inobservancia de dicha regulación.

En 1998 se promulgó el Decreto 990, con contenido específico para la protección de los usuarios de la telefonía móvil celular. A pesar de los esfuerzos para materializar el derecho del consumo, solo hasta el 2011, con la Ley 1480, Colombia desarrolló de forma consolidada un
Estatuto de Protección al Consumidor con sus respectivas responsabilidades, no solo positivizando argumentos, sino materializando la efectividad de la calidad, idoneidad y seguridad de los bienes y servicios consumidos, y haciendo uso de las facultades sancionatorias y mayor énfasis en la función de vigilancia y control de que goza la Superintendencia de Industria y Comercio.

\section{Protección al consumidor en materia de comunicaciones}

Es bien sabido que con la entrada en marcha de la telefonía móvil celular en nuestro país, también llegaron las situaciones de inconformismo de varios consumidores de este servicio, razón por la cual era menester establecer una serie de mecanismos y una normatividad clara para materializar la defensa de los derechos de los usuarios. En la actualidad, la Resolución 3066 de 2011 (Comisión Reguladora de Comunicaciones, 2014) es la norma especial que se aplica en materia de peticiones, quejas y reclamos (PQR) frente al servicio de telefonía celular, y el derecho de petición es el principal mecanismo para salvaguardar los consumidores del servicio.

Como quedó anteriormente expuesto, la entidad encargada de vigilar y controlar lo referente a la protección del consumidor en materia de comunicaciones, es la Superintendencia de Industria y Comercio, a través de la Dirección de Protección a Usuarios de Servicios de Comunicaciones, sus funciones están establecidas en el Decreto 4886 de 2011, en su artículo 13. 


\section{Mecanismos de defensa y trámite}

El usuario o consumidor de alguno de los servicios de comunicaciones, frente a una situación de inconformidad relacionada con el mismo, puede iniciar una actuación como mecanismo de defensa, a fin de que se dirima el conflicto suscitado de la relación contractual con el proveedor del servicio. Dicho procedimiento inicia con la presentación de una petición o queja ante el proveedor, si la respuesta no le es favorable, el usuario está facultado para interponer un recurso de reposición, que es resuelto por la empresa de telefonía celular. Sin embargo, si la desfavorabilidad persiste, la ley prescribe la posibilidad de entablar un recurso de apelación, el cual debe ser presentado de modo subsidiario y simultáneo al de reposición, con el propósito de que el proveedor envíe el expediente a la autoridad que ejerza vigilancia y control, para que esta resuelva el recurso de apelación, que para el caso en particular es la Superintendencia de Industria y Comercio. Se establecen entonces los requisitos y las generalidades de cada uno de estos pasos:

\section{Petición o queja (PQR)}

Al respecto, en la Resolución 3066 de 2011 (Comisión Reguladora de Comunicaciones, 2014) se definen las PQR así: "PQR: Petición, queja o recurso formulado por el usuario ante el proveedor de servicios de comunicaciones, que contribuye al adecuado ejercicio de sus derechos".

De la misma forma, en la citada Resolución se indican las modalidades de dicha petición o queja, que puede ser presentada de manera verbal o escrita. En el primer evento, basta con comunicar al proveedor el nombre completo del peticionario, el número de identificación y el motivo de la inconformidad, el proveedor tiene la posibilidad de responder de la misma forma y debe proporcionar un número de radicado. En el evento de que la PQR sea radicada por escrito, deben contener, por lo menos, el nombre del proveedor al que se dirige, el nombre, identificación, dirección de notificación del usuario, y los hechos en que se fundamenta la solicitud, para efectos de responder las peticiones. El artículo 40 de la mencionada Resolución indica que los proveedores cuentan con un término de quince días hábiles, contados a partir del día siguiente de la fecha de su presentación, para contestar, término que podrá extenderse hasta por quince días hábiles más, para la práctica de pruebas. En caso de no existir respuesta, en dicho período de tiempo operará de pleno derecho el silencio administrativo positivo, y se entenderá que la PQR ha sido resuelta en forma favorable al usuario.

Ahora bien, sobre los medios tecnológicos, electrónicos o físicos asociados con los mecanismos obligatorios de atención al usuario por medio de los cuales el mismo interpone las PQR, la Resolución 3066 de 2011 (Comisión Reguladora de Comunicaciones, 2014), en su artículo 44, consigna que deben existir oficinas físicas de atención al usuario para recibir, atender, tramitar y responder las PQR en todas las capitales de departamento en las cuales presten los servicios a su cargo. Estas oficinas deben ser claramente identificables por parte de los usuarios, 
de manera que no se presente confusión, y con el propósito de evitar el desplazamiento de los usuarios entre diferentes áreas geográficas, en caso de que en determinado municipio no exista una oficina física. Asimismo, en el artículo 45 de la Resolución 3066 de 2011 se ordena al proveedor contar también con oficinas virtuales de atención en su sitio web, en cuyo caso dará respuesta oportuna a las $\mathrm{PQR}$, a través del correo electrónico suministrado por parte del usuario como dirección de notificación. El último medio que debe disponer el proveedor para la presentación de las peticiones o quejas está contenido en el artículo 46 de la mencionada Resolución, y se refiere a la línea gratuita de atención al usuario, que debe estar disponible las veinticuatro horas del día, los siete días de la semana.

La Resolución 3066 también se ocupó de indicar claramente qué debe contener la decisión del proveedor frente a una PQR, así:

\section{ARTÍCULO 49. CONTENIDO DE LAS DECISIO-} NES. Sin perjuicio de lo previsto en la ley, las decisiones adoptadas por los proveedores de servicios de comunicaciones a las PQR formuladas por los usuarios, deben contener como mínimo el resumen de los hechos en que se fundamenta la $\mathrm{PQR}$, la descripción detallada de las acciones adelantadas por el proveedor para la verificación de dichos hechos, las razones jurídicas, técnicas o económicas en que se apoya la decisión, los recursos que proceden contra la misma y la forma y plazo para su presentación. (Comisión Reguladora de Comunicaciones, 2014)

Por último, en cuanto al seguimiento de las PQR, debe precisarse que el usuario tiene derecho a consultar y obtener información precisa en cualquier período sobre el estado del trámite de las PQR, utilizando para ello el Código Único Numérico o radicado debidamente asignado e informado por el proveedor del servicio.

\section{Recurso de reposición}

Frente al tema, el artículo 9 de la Resolución 3066 de 2011 (Comisión Reguladora de Comunicaciones, 2014) presenta una definición de los recursos en general:

Recursos: Manifestaciones de inconformidad por parte del usuario respecto de las decisiones tomadas por el proveedor respecto de una PQR (relacionada con actos de negativa del contrato, suspensión del servicio, terminación del contrato, corte y facturación), mediante la cual el usuario solicita la revisión y reconsideración de la misma. Se refiere tanto a la solicitud del usuario de revisión por parte del proveedor, como a la presentada por el usuario en forma subsidiaria para que la Superintendencia de Industria y Comercio revise y decida de fondo.

En el mismo articulado, se define el recurso de reposición así: "Recurso de reposición: Cualquier manifestación de inconformidad del usuario respecto de la decisión tomada por el proveedor frente a una petición o queja, expresada ante el proveedor para que este mismo aclare, modifique o revoque dicha decisión" (Comisión Reguladora de Comunicaciones, 2014).

El recurso de reposición debe presentarse ante el mismo proveedor que haya decidido la petición o queja, dentro de los cinco días hábiles siguien- 
tes a la notificación de la decisión al usuario. Según el artículo 47 numeral 1 de la Resolución 3066 (Comisión Reguladora de Comunicaciones, 2014), cualquier manifestación de inconformidad respecto de la decisión del proveedor, expresada por el usuario, debe ser atendida y gestionada como recurso de reposición.

Por otra parte, y dependiendo de la modalidad de presentación del recurso, se tendrán en cuenta determinadas reglas: en el evento de que el recurso sea formulado por escrito, el proveedor está en la obligación de entregar un formato en el que se incluirán casillas que le permitan elegir al usuario entre si presenta o no recurso de apelación. Por otra parte, en caso de que el recurso sea recepcionado de forma verbal, el proveedor debe informar de la misma forma la opción al usuario de presentar o no el recurso de apelación, y, adicionalmente, debe almacenar la evidencia de la elección del usuario por un término de por lo menos seis meses.

Cuando el proveedor finalmente resuelve el recurso de reposición y el mismo es notificado al usuario, cuenta con máximo cinco días hábiles para remitir el expediente en medio físico o digitalizado (completo) a la Superintendencia de Industria y Comercio para que resuelva el recurso de apelación.

\section{Recurso de apelación}

La Resolución 3066 de 2011, en su artículo 9 (Comisión Reguladora de Comunicaciones, 2014), define el recurso de apelación de la siguiente forma:
Recurso de Apelación: Cualquier manifestación de inconformidad del usuario respecto de la decisión a ser tomada por el proveedor, para ser revisada y decidida por la Superintendencia de Industria y Comercio -SIC-. Se presenta en subsidio y de manera simultánea al recurso de reposición, es decir, que si el usuario así lo quiere, lo presenta en el mismo momento que presenta el recurso de reposición y, en caso de que el proveedor confirme la negativa frente a las pretensiones del usuario, dicho proveedor deberá entregar el expediente completo a la SIC para que esta lo revise y decida de fondo.

El proveedor deberá informar al usuario sobre el envío del expediente a la Superintendencia de Industria y Comercio, y este puede darle el mismo seguimiento que a una PQR mediante el Código Único Numérico (CUN). Cuando la SIC emite su fallo de fondo en ejercicio de sus funciones jurisdiccionales, el proveedor del servicio cuenta con cinco días para acreditar el cumplimiento de lo ordenado. Si no lo hace se hará acreedor de las sanciones previstas en la ley. Adicionalmente, el proveedor está en la obligación de notificar el contenido de la decisión al usuario en su calidad de reclamante, advirtiéndole que no procede recurso alguno contra tal decisión. 


\section{E. Principales quejas de los usuarios en materia de comunicaciones}

Figura 3. Tipos de queja más frecuentes

\begin{tabular}{|c|c|c|}
\hline & & $\begin{array}{c}\text { \% SOBRE EL } \\
\text { TOTAL DE } \\
\text { QUEJAS POR } \\
\text { OPERADOR }\end{array}$ \\
\hline \multirow{3}{*}{$\begin{array}{l}\text { COMUNICACIÓN } \\
\text { CELULAR S.A. } \\
\text { COMCEL S. } \\
\text { A. (CLARO) }\end{array}$} & $\begin{array}{l}\text { Facturación inde- } \\
\text { bida }\end{array}$ & $44,3 \%$ \\
\hline & \begin{tabular}{|l} 
Cobro indebido de \\
servicios comple- \\
mentarios \\
\end{tabular} & $20,0 \%$ \\
\hline & $\begin{array}{l}\text { Deficiencia en la } \\
\text { calidad y prestación } \\
\text { del servicio }\end{array}$ & $17,8 \%$ \\
\hline \multirow{4}{*}{$\begin{array}{l}\text { TELEFÓNICA MÓ- } \\
\text { VILES COLOMBIA } \\
\text { S. A. (MOVISTAR) }\end{array}$} & $\begin{array}{l}\text { Facturación inde- } \\
\text { bida }\end{array}$ & $29,2 \%$ \\
\hline & $\begin{array}{l}\text { Negación de llama- } \\
\text { das de fijo a celular } \\
\text { o trunking }\end{array}$ & $15,5 \%$ \\
\hline & $\begin{array}{l}\text { Reporte centrales } \\
\text { de riesgo }\end{array}$ & $7,9 \%$ \\
\hline & Otros & $35,7 \%$ \\
\hline \multirow{3}{*}{$\begin{array}{l}\text { COLOMBIA } \\
\text { MÓVIL S. A. ESP. } \\
\text { (TIGO) }\end{array}$} & $\begin{array}{l}\text { Facturación inde- } \\
\text { bida }\end{array}$ & $29,2 \%$ \\
\hline & $\begin{array}{l}\text { Deficiencia en la } \\
\text { calidad y prestación } \\
\text { del servicio } \\
\end{array}$ & $28,9 \%$ \\
\hline & $\begin{array}{l}\text { Negación de llama- } \\
\text { das de fijo a celular } \\
\text { o trunking }\end{array}$ & $18,1 \%$ \\
\hline \multirow{3}{*}{ UFF MÓVIL } & \begin{tabular}{|l}
$\begin{array}{l}\text { No abono opor- } \\
\text { tuno }\end{array}$ \\
\end{tabular} & $58,0 \%$ \\
\hline & $\begin{array}{l}\text { Negación de llama- } \\
\text { das de fijo a celular } \\
\text { o trunking }\end{array}$ & $14,2 \%$ \\
\hline & \begin{tabular}{|l} 
Cobro indebido de \\
servicios comple- \\
mentarios \\
\end{tabular} & $14,2 \%$ \\
\hline \multirow{2}{*}{$\begin{array}{l}\text { UNE EPM TELE- } \\
\text { COMUNICACIO- } \\
\text { NES S.A. E.S.P. }\end{array}$} & $\begin{array}{l}\text { Facturación inde- } \\
\text { bida }\end{array}$ & $80,0 \%$ \\
\hline & $\begin{array}{l}\text { Deficiencia en la } \\
\text { calidad y prestación } \\
\text { del servicio }\end{array}$ & $20,0 \%$ \\
\hline
\end{tabular}

Fuente: SIC, Informe frente al primer trimestre de 2012.
De acuerdo con la Figura 3, se evidencia una constante dentro de las quejas presentadas ante los diferentes operadores, en su orden, la deficiencia en la calidad y prestación del servicio y la facturación indebida. Dichos inconformismos están directamente relacionados con las obligaciones de las empresas de telefonía celular y las directrices de prestación del servicio, establecidas en la Resolución 3066 de 2011.

Frente al motivo más frecuente de queja cabe resaltar que la empresa de telefonía celular tiene el compromiso de prestar el servicio en los términos establecidos en el contrato suscrito con el usuario, por lo tanto, la Resolución 3066 de 2011 (Comisión Reguladora de Comunicaciones, 2014), establece al respecto:

\section{ARTÍCULO 33. COMPENSACIÓN POR FALTA DE} DISPONIBILIDAD DE LOS SERVICIOS. EI incumplimiento de las condiciones de continuidad a las que está sujeta la prestación de servicios de comunicaciones, por causas imputables al proveedor, da derecho al usuario que celebró el contrato a recibir una compensación por el tiempo en que el servicio no estuvo disponible o a terminar el contrato, sin lugar, en este último caso, al pago de sumas asociadas a la cláusula de permanencia mínima. Lo anterior, a excepción de los eventos previstos en el artículo 34 de la presente resolución.

La determinación de la compensación y el valor de esta se realizará de acuerdo con la metodología descrita en el Anexo I de la presente resolución.

PARÁGRAFO. Siempre que se tramite una queja relacionada con la falta de disponibilidad del 
servicio, aún en los casos en que el usuario no haya solicitado la compensación, el proveedor deberá de oficio analizar su procedencia e informar al usuario si hay lugar o no a la compensación. En caso de que la queja sea resuelta en sentido favorable al usuario, procederá la compensación o la terminación del contrato, según la elección del usuario.

También es importante mencionar la consecuencia de la no prestación del servicio con la calidad y efectividad que indica la norma, para ello, la Resolución 3066 (Comisión Reguladora de Comunicaciones, 2014), consagra: "ARTícu-

LO 63. IMPROCEDENCIA DEL COBRO. LOS prOveedores de servicios de comunicaciones no podrán cobrar servicios no prestados, ni tarifas ni conceptos diferentes a los informados y aceptados previamente por el usuario, o previstos en las condiciones de los contratos".

De acuerdo con la normatividad precitada, para los casos en los cuales se presenta una falla, suspensión, entre otras, del servicio imputable al proveedor, los valores que se generen en ese lapso no podrán ser cobrados al usuario.

Frente al segundo motivo de queja, facturación indebida, esta se presenta cuando en la factura se cobran servicios que no fueron contratados o utilizados por el usuario. En primer lugar, debe anotarse que la Resolución 3066 (Comisión Reguladora de Comunicaciones, 2014), en su artículo 26, consigna que si los mismos son aceptados por el usuario, este adquiere la obligación de cancelarlos, caso contrario a cuando se evidencia una flagrante modificación unilateral sin consentimiento del contrato, en este caso el usuario estará exonerado de los pagos generados por los servicios adicionales no contratados.

\section{F. Casos resueltos por la Superintendencia de Industria $y$ comercio en materia de TMC}

Como se podrá observar más adelante, el número de quejas radicadas en empresas es bastante alto, muchas de estas inconformidades llegan a conocimiento de la SIC, al interponerse recurso de apelación cuando el proveedor de telefonía móvil celular haya resuelto el recurso de reposición de forma desfavorable. A continuación presentaremos algunos de estos casos. Por medio de la Resolución 1294 de 2011, la SIC decide revocar la decisión de Tigo de cobrar una sanción por retiro anticipado a un suscriptor que decide terminar el contrato de Internet móvil por la mala calidad del mismo. La Superintendencia consideró que el no prestar el servicio de forma eficiente exime al usuario de los pagos de los períodos en que se presentaron fallas, y adicionalmente lo faculta para terminar el contrato, aún con un período de permanencia pendiente, sin lugar a ningún tipo de cobro (www.sic.gov. co, 2011).

En otro caso, a través de la Resolución 6280 de 2011 la SIC revocó la decisión empresarial proferida por el operador Movistar. Esta empresa no acogía las pretensiones de un usuario del municipio de Soacha que no había podido utilizar el Internet móvil por la falta de cobertura en la zona. La SIC concluyó que el proveedor del servicio debió procurar superar las limitaciones 
técnicas existentes respecto al Internet ofrecido, y que de no poder cumplir con dicho compromiso debía informar al suscriptor para que él mismo pudiera decidir entre continuar o no con el servicio, por lo que ordenó descontar el cargo básico cobrado en el período objeto de reclamo hasta el momento en que cesó la falla del servicio (www.sic.gov.co, 2011).

Por último, en la Resolución 14577 de 2012 la SIC ordenó revocar unos cobros de unas Ilamadas adicionales a tres líneas celulares que el usuario afirmaba no haber realizado. La Superintendencia consideró que el plan contratado por el suscriptor no contemplaba servicios adicionales y que estos serían cobrados en la medida en que se consuman, por lo que es deber del operador asumir la carga probatoria para demostrar la relación clara entre la prestación del servicio y su facturación. La compañía no probó dicha situación de forma suficiente, por lo que se concluyó que los consumos adicionales facturados no fueron realizados, y por ende su facturación correspondió a un error del proveedor (www.sic.gov.co, 2012).

\section{G. Informe abonados y variación en la telefonía móvil celular}

Desde 2010, en Colombia el crecimiento en número de abonados (números telefónicos) ha sido significativo, teniendo en cuenta que este mercado es relativamente nuevo, tal y como se evidencia en la siguiente gráfica:

\section{Figura 4. Abonados telefonía móvil - Nivel nacional}

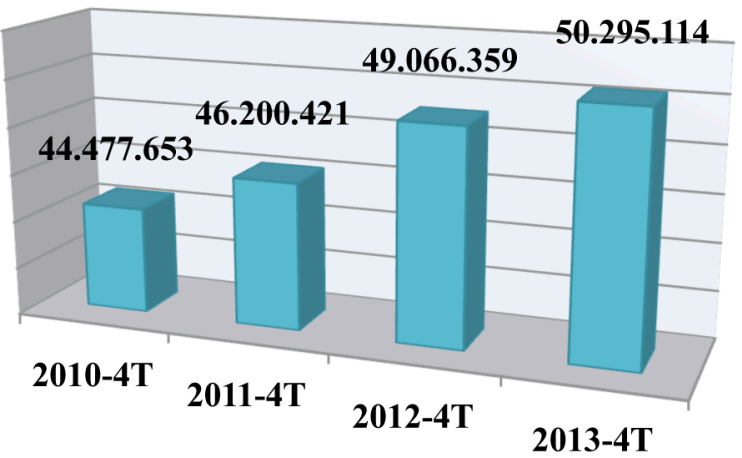

Fuente: SIC, Boletín trimestral de las TIC, Cifras del cuarto trimestre de 2013 , datos recabados por las autoras.

Como se evidencia en la Figura 4, en el cuarto trimestre de 2013 Colombia contaba con 50.295.114 números de abonados activos, lo que significa un aumento en 5.817.461 frente a lo reportado en el último trimestre de 2010, es decir, por cada 100 habitantes existen 106,7 números de abonados en servicio. (Boletín Trimestral de las TIC - cifras cuarto trimestre de 2013).

A medida que avanza la tecnología y aunado a las facilidades de adquisición de los servicios de telefonía móvil celular que hoy existen en el país, es obvio el incremento que se seguirá presentando respecto de los abonados activos. 
Figura 5. Participación total de abonados por proveedor - Nivel nacional

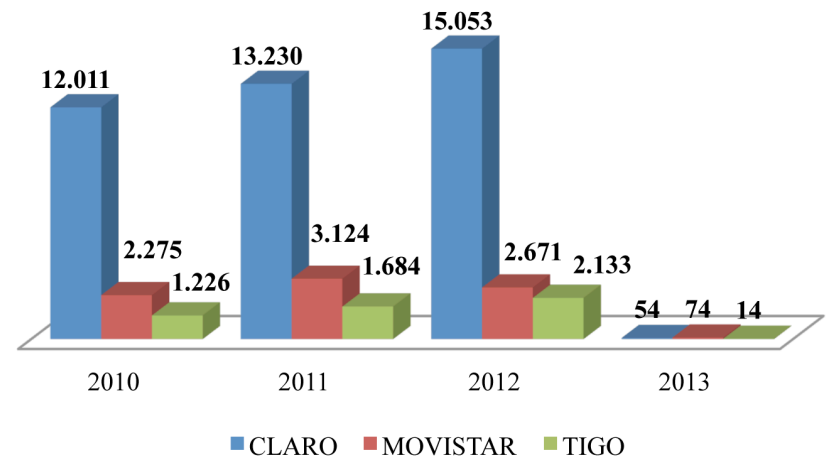

Fuente: Boletín trimestral de las TIC, Cifras del cuarto trimestre de 2013, datos recabados por las autoras.

\section{SANCIONES}

Como se mencionó en acápites anteriores, la entidad encargada de vigilar y controlar lo referente a la protección del consumidor en materia de comunicaciones es la Superintendencia de Industria y Comercio, a través de la oficina de Dirección de Protección a Usuarios de Servicios de Comunicaciones. Sus funciones están establecidas en el artículo 13 del Decreto 4886 de 2011. En desarrollo de la función de vigilancia y control y la potestad sancionatoria otorgada por la ley, esta entidad ha impuesto una serie de sanciones a los operadores de telefonía móvil celular por la falla en la prestación del servicio, como resultado de las múltiples quejas interpuestas por los usuarios.
Figura 6. Número de quejas radicadas en sede empresa

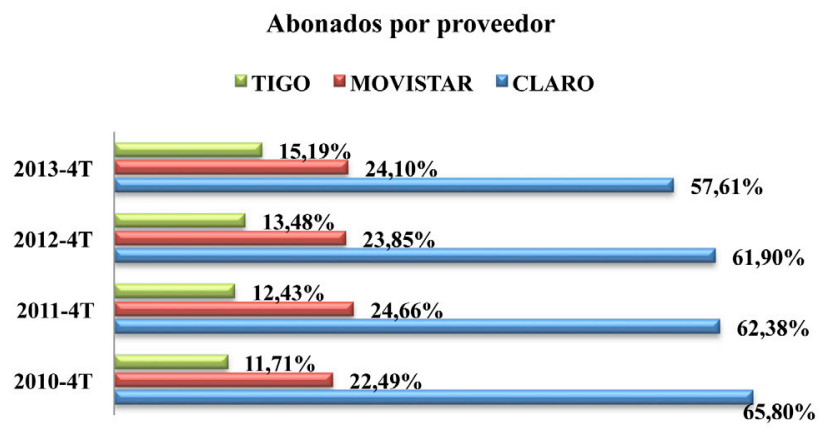

Fuente: SIC, datos recabados por las autoras.

En la anterior gráfica se evidencian el número de quejas presentadas ante los operadores de telefonía celular y el aumento significativo presentado desde el año 2010 hasta el 2012, donde tuvo su mayor índice y el valor más alto en cuanto a multas se refiere; no obstante, para el año 2013 tuvieron una disminución sorprendente.

Por otra parte, y frente a las sanciones impuestas por parte de la SIC en materia de protección al consumidor de servicios de telefonía móvil celular, se tien

\section{Figura 7. Valor sanciones impuestas por la SIC}

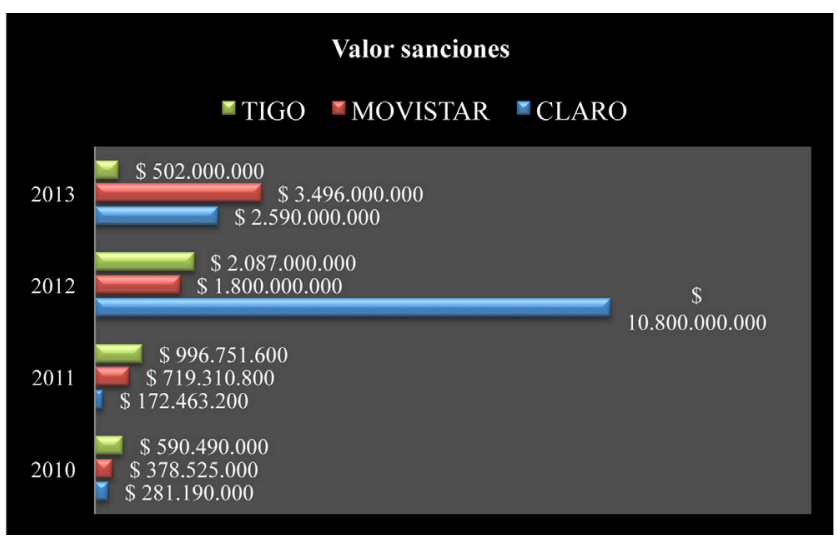

Fuente: (W Radio, 2013), (bluradio.com, 2013), (Instituto Nacional de Contadores públicos, 2014), información consolidada por las autoras. 
A pesar de la disminución que se presenta en el número de quejas en el año 2013, el valor de las sanciones impuestas por parte de la SIC a los operadores de telefonía celular continúa en aumento año a año, excepto en el caso de Claro, que tuvo una importante reducción en el último trimestre de 2013. Sin embargo, frente a los reportes de los demás años se evidencia que el valor de las multas presenta una variación importante, y que lleva a concluir que las mismas deben ser más fuertes para generar el impacto y resultado deseado.

La sanción más alta que ha impuesto la SIC en materia de protección al consumidor de servicios de telefonía móvil celular se presentó en el primer trimestre de 2013, cuando sancionó a la empresa Comunicación Celular S.A. Comcel, por un valor de $\$ 566.700 .000$ millones de pesos, un valor relativamente bajo en comparación con las fallas contantes en la prestación del servicio de este operador (Superintendencia de Industria y Comercio, 2014) y que, adicionalmente, no repercute de forma importante en las finanzas del operador, si tenemos en cuenta que las utilidades netas de dicha compañía en los dos últimos años ascienden a 4,44 billones de pesos (Portafolio.co. S.F.).

\section{CONCLUSIONES}

La telefonía móvil se ha transformado en una herramienta básica de comunicación masiva, con la que cuentan casi todos los habitantes de nuestro territorio, independientemente de su situación socioeconómica. Ahora, como con- secuencia del crecimiento del servicio en los últimos años, también llegaron los inconformismos. Los usuarios del servicio de telefonía móvil en Colombia se están quejando todos los días por el ineficiente servicio recibido por parte de las distintas empresas de comunicaciones, sin tener hasta el día de hoy una solución eficaz a dicha problemática. Esto nos llevó a preguntarnos si la SIC, que es la entidad encargada de ejercer las funciones de vigilancia y control frente a este servicio, está desarrollando las acciones necesarias tendientes a su normalización, y si dichas acciones son realmente eficaces.

Por expreso mandato constitucional, la función pública debe regirse por los principios de eficacia y eficiencia en el servicio. Específicamente, el principio de eficacia de la función administrativa impide a las autoridades administrativas permanecer indiferentes frente a situaciones que afecten a los ciudadanos, razón por la cual se encuentran en la obligación de efectuar y desarroIlar todas las herramientas encaminadas a evitar que la ciudadanía se vea perturbada, en este caso, por las actuaciones de las empresas prestadoras del servicio de telefonía móvil celular.

La facultad sancionatoria de las Superintendencias se presenta para hacer cumplir un cuerpo normativo, y se traduce en un verdadero control represivo para la protección efectiva de los derechos de los ciudadanos, convirtiéndose en la principal herramienta de que goza el Estado para efectivizar su actividad.

Por otro lado, y en consonancia con la Ley 1341 de 2009 y la Circular 00003 del 20 de agosto de 
2009 del Mintic, la SIC es el organismo competente para ejercer las funciones de inspección, vigilancia y control de los diferentes operadores de comunicaciones y la protección de los usuarios y suscriptores de dichos servicios.

De acuerdo con los diferentes datos estadísticos presentados a lo largo de esta investigación, hay varios hechos que quedan en evidencia, el principal de ellos es que en lugar de disminuir el número de quejas por parte de los usuarios del servicio de telefonía celular directamente a la SIC, las mismas tuvieron un aumento significativo desde el año 2010 hasta el 2012, en el que tuvo su mayor índice y el valor más alto en cuanto a multas se refiere. No obstante, para el año 2013 tuvieron una disminución sorprendente. Pese a lo anterior, el número de $\mathrm{PQR}$ en sede empresa no ha presentado disminución.

Por otro lado, los tiempos de respuesta frente a los recursos de apelación no son respetados por los operadores de telefonía celular. Sin embargo, se han impuesto un número significativo de sanciones que han tenido el efecto esperado, puesto que el número de $\mathrm{PQR}$ que Ilegaron directamente a la entidad disminuyó durante el último año, al ser solucionados los inconvenientes en sede empresa. Esto nos lleva a la conclusión de que existe, en parte, la eficacia esperada de la función de control de la SIC. No obstante, y en cuanto a la función de vigilancia, según los últimos datos que se tienen, con corte al primer semestre de 2013, los usuarios radicaron más de $\mathbf{4 9}$ millones de peticiones, quejas y recursos, según información recopilada por la Superintendencia de Industria y Comercio. Esto evidencia que en dicho aspecto no es eficaz la labor de vigilancia de dicha entidad.

El problema no está en un vacío legal, pues es de resaltar la importante labor que ha cumplido la Comisión de Regulación de Comunicaciones, con la expedición de las resoluciones 3066 de 2011 y 4296 de 2013 (compensación automática de minutos), que son bastante completas, claras y específicas al contemplar las principales problemáticas con el servicio. El inconveniente real se encuentra en la eficacia de la labor de control y vigilancia que efectúa la SIC para propender porque dichos cuerpos normativos sean cabalmente cumplidos, puesto que si bien las quejas que se radicaron directamente ante dicha autoridad disminuyeron, las PQR en sede empresa no lo han hecho. Aún persisten muchos inconformismos de los usuarios frente al servicio, el cual no se está prestando en las estrictas condiciones que señalan las resoluciones.

Frente a este punto se debe aclarar que si bien se impuso una sanción histórica a Comcel por valor de 87000 millones de pesos (www.sic.gov. co, 2013), confirmada mediante Resolución No. 66934 del 19 de noviembre de 2013, fue la Delegatura de Protección de la Competencia la que la impuso, por considerar que dicha empresa de telefonía celular desarrolló prácticas restrictivas de la competencia al realizar conductas relacionadas con el bloqueo de bandas de equipos móviles celulares, lo que restringía a los usuarios a pasarse a otros operadores móviles. Pero no fue una sanción de la Delegatura en su dirección investigativa, como consecuencia de las cons- 
tantes quejas de los usuarios frente a los temas que ya se enunciaron anteriormente.

En ese orden de ideas, existen varias herramientas que debería tener en cuenta la Superintendencia de Industria y Comercio para hacer más efectiva su labor. En primer lugar, las sanciones que se han interpuesto a los diferentes proveedores del servicio de telefonía móvil celular por transgresiones al régimen de protección de los usuarios de dicho servicio no han sido lo suficientemente rigurosas, es decir, a la empresa le resulta más rentable pagar las sanciones que le impone este organismo, que invertir en el fortalecimiento de la infraestructura y personal necesario para prestar un servicio óptimo, en los términos establecidos en la Resolución 3066 de 2011. En segundo lugar, deben mejorarse de forma prioritaria los tiempos de respuesta de la entidad frente a los recursos de apelación, puesto que tardan demasiado en ser resueltos. Si bien es cierto que los fallos de la SIC son prousuario, ese gran lapso genera desconfianza de los usuarios frente a la efectividad de este mecanismo, desembocando en que en muchas ocasiones las reclamaciones simplemente se queden en sede empresa.

Por último, debe reevaluarse la cantidad de espacio del espectro electromagnético otorgado a los proveedores del servicio de telefonía celular, pues es evidente el crecimiento del servicio. Los celulares ya no solamente son utilizados para efectuar llamadas y enviar SMS, sino que además se están generando conexiones a Internet desde estos dispositivos móviles, con todo lo que esto implica (conexión a redes sociales, bús- quedas de información, GPS, envío y recepción de correos electrónicos, etc), todo lo anterior, en la misma franja de espacio. Este último punto es de gran importancia, pues los países más competitivos a nivel mundial (Noruega, Francia, Inglaterra, Estados Unidos y Canadá) tienen una gran cantidad de espectro asignado a los proveedores del servicio de telefonía móvil celular, lo que demuestra que, además de obtener un servicio de mejor calidad, repercute además en el índice de competitividad global de un país, según datos y cifras manejados por la GSMA.

De acuerdo con todo lo expuesto, es claro que la SIC tiene grandes compromisos por cumplir, y varias medidas que implementar a fin de atender con la eficacia esperada las necesidades que requiere el sector de la telefonía celular y así orientarse al mejoramiento del servicio para todos los usuarios y suscriptores.

La imposición de las millonarias multas por parte de la SIC debe tener repercusión entre los operadores del servicio, estas deben verse materializadas en la eficiente prestación del servicio y en el ejercicio de la función de vigilancia y control de este organismo, en desarrollo de la protección al consumidor.

\section{Bibliografía}

Adecom, movilidad y eficiencia (mayo de 2001).

Recuperado de www.adecom.biz/pdf/pdf_ agosto2005/La\%20evolucion\%20de\%20 la\%20telefonia\%20movil.pdf 
Agencia Nacional del Espectro (26 de agosto de 2013). Recuperado de http://www.ane. gov.co/index.php/conozca-la-ane/que-es-elespectro.html

Archila, M. F. (16 de marzo de 2012). Recuperado de http://bodegasic.sic.gov.co/actos/documentos/Docs017/docs100/2012/20120 14577RE/2012014577RE0000000001.pdf

bluradio.com (11 de febrero de 2013). Recuperado de http://www.bluradio.com/19010/ millonarias-multas-en-2012-los-operadoresde-telefonia-movil-en-colombia

Celulares móviles (4 de mayo de 2012). Recuperado de http://celularesmoviles1.blogspot. com/2012/05/historia-telefonia-celular-omovil-en.html

Comisión Reguladora de Comunicaciones (15 de febrero de 2014). Recuperado de de http://www.crcom.gov.co

Congreso de la República (30 de julio de 2009). Ley 1341, Bogotá, Colombia.

Consitución Política de Colombia (2013). Bogotá: LEGIS.

Contraloría General de la República (2010). Estado actual del servicio de telefonía móvil en Colombia. Bogotá.

Corte Constitucional. Sentencia C-160 del 29 de abril de 1998.
Corte Constitucional. Sentencia C-337 del 19 de agosto de 1993.

Corte Constitucional. Sentencia C-397 del 7 de septiembre de 1995.

Corte Constitucional. Sentencia C-506 del 3 de julio de 2002.

Corte Constitucional. Sentencia C-818 del 9 de agosto de 2005.

Corte Constitucional. Sentencia C-853 del 17 de agosto de 2005.

Corte Constitucional. Sentencia SU086 del 17 de febrero de 1999.

Corte Constitucional. Sentencia T-068 del 5 de marzo de 1998.

Corte Constitucional. Sentencia T-360 de 11 de mayo de 2010.

Corte Constitucional. Sentencia T-559 de 6 de octubre de 1998.

Corte Constitucional. Sentencia de T-597 de 6 de noviembre de 1996.

Corte Constitucional. Sentencia de T-733 de 15 de Octubre de 2009.

Corte Suprema de Justicia (15 de mayo de 2008). Alcibiades Salamanca León Vs. Tribunal Superior de Yopal, 29206.

Corte Suprema de Justicia. Servicio aéreo del Vaupés - Selva Limitada Vs. Fábrica estatal 
de aviación de KIEV - AVIANT - , 50001-3103001-1999-04421-01, 3 de mayo de 2005.

Decreto 1130 (29 de junio de 1999). Bogotá.

Decreto 4886 (23 de diciembre de 2011). Bogotá.

Gonzalez, R. L. Recuperado de https://riunet.upv. es/bitstream/handle/10251/19023/Memoria_Lizon_Gonzalez_Roberto.pdf?sequence $=1$

https//www.rae.es (21 de agosto de 2013).

Imprenta Nacional de Colombia (30 de julio de 2009). Recuperado de http://www.imprenta. gov.co/portal/page/portal/inicio\#

Instituto Nacional de Contadores públicos (19 de marzo de 2014). Recuperado de http:// www.incp.org.co/Site/2011/info/archivos/ CelularesEnero.pdf

kienyke.com (10 de abril de 2013). Recuperado de http://www.kienyke.com/historias/virginmobile-juan-guillermo-velez-cobro-por-segundo-colombia/

Latorre, N. R. (04 de marzo de 2013). Recuperado de LAUD: http://laud.udistrital.edu.co/ noticias/despu\%C3\%A9s-de-40-a\%C3\%B1osya-son-alrededor-de-6200-millones-usuariosnivel-mundial-hablando-por-ce

Ley 1151, artículo 71 (24 de julio de 2007). Obtenido de Imprenta Nacional de Colombia: http://www.imprenta.gov.co/portal/page/ portal/inicio\#
López, G. E. (2010). Comentarios a la Ley de Tecnologías de la Información y las Comunicaciones - TIC. Bogotá: Universidad Externado de Colombia.

Mejía, A. J. (11 de febrero de 2011). Recuperado de http://bodegasic.sic.gov.co/actos/documentos/Docs017/docs100/2011/20110 06280RE/2011006280RE0000000001.pdf

Ministerio de Tecnologías de la Información y las Comunicaciones. Recuperado de http://colombiatic.mintic.gov.co/602/articles-5550_ archivo_pdf.pdf

Parejo, A. L. (1998). Perspectivas del derecho administrativo para el próximo milenio. Bogotá: Ibañez.

Penagos, G. (2004). Derecho administrativo, nuevas tendencias (5. ${ }^{a}$ ed.). Bogotá: Doctrina y Ley LTDA.

Política de espectro y la promoción de la B.Ancha (15 de julio de 2010). Recuperado de http:// www.telecomunicaciones.org.uy/web/images/pdf/GSMA.pdf

Portafolio.co. S.F. Recuperado de http://m. portafolio.co/negocios/utilidad-comcel2013-fue-204-billones/?tamano=grande

Protección, garantías y eficacia de los derechos del consumidor en Colombia. (1 de enerojunio de 2010). Recuperado de file:///C:/ Users/TAIWAN-6/Downloads/Doc\% 20 Protecci\%C3\%B3n\%20consumidor.pdf 
Ramírez, T. M. (2007). Postura de la Corte Constitucional en relación con el poder sancionador de la administracion. Revista de Derecho, 28 (300-328).

Salazar, E. C. Recuperado de www.utp.edu. co/.../TECNOLOGIA\%20CELULAR\%20salvador.ppt

Sánchez, A. L. (11 de febrero de 2011). Recuperado de http://bodegasic.sic.gov.co/actos/ documentos/Docs017/docs100/2011/201 1006280RE/2011006280RE0000000001. pdf

Superintendencia de Industria y Comercio. Recuperado de htpps//www.sic.gov.co

Superintendencia de Industria y Comercio (19 de marzo de 2014). Recuperado de http:// www.sic.gov.co/superindustria-sanciona-acomcel-s.a.-claro-por-activar-roaming-internacional-sin-solicitud-previa-y-expresa-de-losusuarios

Torres, N. Á. (2002). Telecomunicaciones y telemática de las señales de humo a las actividades por internet. Bogotá: Escuela colombiana de Ingenieria.

Unidades de medida de almacenamiento de información. Recuperado de http://unidadesdealmacenamientodeinformacion.blogspot. com/

Vidal, P. J., Díaz, P. V., y Rodríguez, G. A. (2005). Temas de derecho administrativo contemporáneo. Bogotá: Rosarista.

WRadio. (11 de febrero de 2013). Recuperado de http://www.wradio.com.co/noticias/econo$\mathrm{mia} / \mathrm{multas}$-de-la-superindustria-en-2012-totalizaron-26546-millones/20130211/ nota/1840330.aspx

www.sic.gov.co. (19 de noviembre de 2013). Recuperado de http://www.sic.gov.co/drupal/ noticias/node/6534

www.timerime.com. Recuperado de http:// timerime.com/es/evento/1364867/ Nace+la+telefona+celular/ 